\title{
Specific Attention Areas in Scar Management: Management of Atrophic Scars
}

Matteo Tretti Clementoni and Ernest Azzopardi

\section{Contents}

\subsection{Background -354}

41.1.1 Common Principles - 354

41.2 Atrophic Acne Vulgaris Scarring - 354

41.2.1 Resurfacing and Tightening Techniques -354

41.2.2 Dermal Lift Techniques - 355

41.2.3 Volume-Imparting Techniques - 356

41.2.4 Isotretinoin Treatment - 356

41.2.5 State-of-the-Art and Combinatorial Approaches - 356

41.3 Striae Albae - 358

41.4 Burn Atrophic Scars - 360

41.5 Conclusion -361

References - 361 


\subsection{Background}

Atrophic scars represent some of the most difficult and insidious pathologies confronting the reconstructive surgeon. Deriving from the ancient Greek "a-trophos" (wasted), the term presents a vivid representation of the clinical picture and an area of scar management particularly worthy of specific attention.

The atrophic scars typically develop as a result of an intracutaneous inflammatory process. Rather than exuberant inflammation, the process results in reduced matrix regeneration and focally reduced collagen production. Focal contraction of the scar tissue will result in uneven soft tissue defects. Clinically, these result in contour defects on the surface of the skin [1].

Several pathologies may result in atrophic scars [2], This chapter is intended for the experienced laser practitioner tackling three clinical conditions presenting to the reconstructive specialties, often as a last resort after exhaustive traditional management: acne, striae albae, and burns. It explores common principles, followed by state-of-the-art management and evaluation of the senior author's experience.

\subsubsection{Common Principles}

These atrophic conditions wound both tissue and psyche. They tend to be underestimated causes of significant morbidity for the individual patient who often either loses all hope of amelioration or presents with unrealistic expectation. Therefore, its appropriate management entails identification of their concern, their attitude toward the risk/benefit of the management proposed, and setting their expectations at an appropriate and realistic level. It is important to emphasize that current treatment modalities can improve but cannot completely remove atrophic scars. Scarring from acne vulgaris and burns has been associated to a range of mental health issues including depression as well as embarrassment, poor self-esteem, and general social impairment. Early and appropriate involvement of multidisciplinary opinion is key [3, 4].

Appropriate clinical documentation not only helps set the baseline at presentation but also allows the patient to observe progress and build confidence. Both two-dimensional photography and three-dimensional photography are useful adjuncts in management, given reproducible conditions and serial repetition.

Further, an objective grading of the condition is key to identify appropriate therapeutic options in mind. While classification systems are extensively discussed elsewhere, it is our experience that the use of one over the other is not in itself as important as consistency, and familiarity with one system, geared toward a therapeutic solution.

\subsection{Atrophic Acne Vulgaris Scarring}

Atrophic scarring is substantially more common than hypertrophic [5]. Being able to deconstruct the presentation into the component symptoms is crucial. Often the components of the presenting complaint are a mixture of contour and dyschromia, which can be general or specific to particular areas or even single scars. It is important to enquire about the physical consequences which the patient perceives, such as the inability to apply makeup, which are key areas of concern, past treatment regimes, and the frequency of recrudescence. Tendency to hypertrophic, keloid, or poor scarring is asked. Enquiring about postoperative social commitments is important, considering the variation in recovery times with the various treatments while sun exposure without adequate protection may dramatically alter the result and incidence of complications. Examination establishes skin type and excludes residual active inflammation, extent, and grade of disease. Application of the Goodman and Baron classification imparts some degree of objectivity in concluding one's deliberations to focus on the appropriate therapeutic modalities (• Table 41.1).

Management of atrophic acne scarring depends on the infrastructure and equipment available to the practitioner; therefore, a critical appraisal of traditional methods is presented first, followed by state-of-the-art methods and our experience thereafter. For ease of reference, these techniques are grouped by their main mode of action into resurfacing and tightening, dermal lifting techniques, and dermal volumization techniques.

\subsubsection{Resurfacing and Tightening Techniques}

\subsubsection{Microdermabrasion}

Microdermabrasion is a minimally invasive technique that improves texture but only addresses superficial scars, although its combination with aminolevulinic acid photodynamic therapy (ALA-PDT) is more effective, based on RCT evidence [7]. In principle, subsequent wound remodeling results in neocollagenesis and hence increased dermal thickness. Its main use is for welldefined superficial scars with distinct borders or broadbased scars with indistinct borders. Its main drawbacks are high operator dependence and a suboptimal safety profile. Further adverse effects may include dyschromia and scarring. For these reasons it has been largely replaced by laser. 
- Table 41.1 Post-acne scars, qualitative global grading system (Goodman and Baron) [6]

\begin{tabular}{|c|c|c|}
\hline Grade & $\begin{array}{l}\text { Disease } \\
\text { level }\end{array}$ & Features and tests \\
\hline I & Macular & $\begin{array}{l}\text { These scars are erythematous, hyper- or } \\
\text { hypopigmented macules } \\
\text { They do not represent a problem of } \\
\text { contour but that of color }\end{array}$ \\
\hline II & Mild & $\begin{array}{l}\text { Mild atrophic or hypertrophic scars } \\
\text { that may not be obvious at social } \\
\text { distances of } 0.5 \mathrm{~m} \text { or greater and may } \\
\text { be covered adequately by makeup or } \\
\text { the normal shadow of shaved beard } \\
\text { hair in men or normal body hair if } \\
\text { extrafacial }\end{array}$ \\
\hline III & Moderate & $\begin{array}{l}\text { Moderate atrophic or hypertrophic } \\
\text { scarring that is obvious at social } \\
\text { distances of } 0.5 \mathrm{~m} \text { or greater and is not } \\
\text { covered easily by makeup or the } \\
\text { normal shadow of shaved beard hair } \\
\text { in men or body hair if extrafacial. Can } \\
\text { be flattened by manual stretching of } \\
\text { the skin (if atrophic) }\end{array}$ \\
\hline IV & Severe & $\begin{array}{l}\text { Severe atrophic or hypertrophic } \\
\text { scarring that is evident at social } \\
\text { distances greater than } 0.5 \mathrm{~m} \text { and is not } \\
\text { covered easily by makeup or the normal } \\
\text { shadow of shaved beard hair in men or } \\
\text { body hair if extrafacial. Cannot be } \\
\text { flattened by manual stretching of the } \\
\text { skin }\end{array}$ \\
\hline
\end{tabular}

\subsubsection{Chemical Peels and Microneedling}

Chemical peels can improve pigmentation and tone and texture. Bhargava et al. reported that glycolic acid $(35 \%)$ peels and salicylic $(20 \%)$ - mandelic acid $(10 \%)$ peels were more effective for ice-pick than boxcar scars. Twiceweekly stronger strength peels seem to be more effective than daily low-strength creams. Trichloroacetic acid $(35 \%)$ peels with a short downtime seemed to be particularly effective in darker skin types. Yet others combine needling with TCA peels to good effect. Caution needs to be taken in view of several potential adverse effects including prolonged erythema and post-inflammatory hyperpigmentation. These side effects are more prevalent but by no means limited to deep peels. Paradoxically, very high concentrations of TCA have demonstrated high efficacy in atrophic scars, and boxcar scars in particular, and have been rebranded as chemical reconstruction of skin scars (CROSS). Skin needling is another method, based on the principle of percutaneous induction of collagen, creating dermal microclefts, with collagenesis resulting from the cascade of growth factors unleashed by the wound-healing process. It appears to be more effective on rolling scars, and collagen deposition happens slowly, with the final result taking several repeat sessions and up to a year to be complete. Needling seems to confer added value as a method for transcutaneous drug delivery. Several such applications have been reported, such as combinations with TCA, platelet-rich plasma (PRP), and CROSS. Current best evidence suggests that results are operator-dependent, frequencydependent, and concentration-dependent and that depth and degree of post-inflammatory hyperpigmentation are unpredictable, requiring experience and expertise; for this reason, the authors have moved away from these techniques toward light and laser therapy.

\subsubsection{Dermal Lift Techniques}

\subsubsection{Punch Excision}

Punch excision is a simple and quick technique that converts a discrete atrophic scar into a well-apposed, welloriented surgical "healthy scar" which is easier to manage by both surgeon and patient. An appropriately sized punch biopsy is used to perform full-thickness excision. The wound is then sutured along relaxed skin tension lines (RSTLs). Observing the elongation of the circle into an ellipse with tension allows the practitioner to choose the optimal orientation for closure. It is also useful to avoid closely spaced defects and thus excess traction. Punch excision is replaced by sharp elliptical excision to avoid standing cone formation, when the defect is larger than $3 \mathrm{~mm}$. Once healed, the resulting surgical wounds can be incorporated into laser remodeling.

Punch grafting replaces the punch excision with a similarly sized graft, of better quality in principle, but is laborious and often results in suboptimal color and textural mismatch. Punch elevation is another less commonly practiced technique reserved for boxcar scars with sharp edges and normal bases. The punch biopsy tool is used to excise the scar and its walls down to fat. This is followed by careful tissue elevation for the surface to sit slightly proud of surrounding skin to allow for subsequent retraction. The punched base is then secured. While both techniques are described in the literature, a clear advantage of either compared to punch excision and suturing, or our preferred techniques illustrated hereunder, is not immediately evident.

\subsubsection{Subcutaneous Incision}

Subcutaneous incision (subcision) frees dermis tethered by fibrous bands causing rolling scars. This technique employs a needle (ideally tribevelled) by severing adherent bands in a subcutaneous plane. Given adequate infiltration with adrenaline-containing local anesthetic, risk of hematoma formation is minimized. The technique does, however, run the risk of subcutaneous nodule formation. 


\subsubsection{Volume-Imparting Techniques}

\subsubsection{Filling Techniques}

Both autologous (lipotransfer) and alloplast (nonanimal, cross-linked hyaluronic acid, NAHA) have been described to improve the volume underneath atrophic scars. The technique mandates prior release of the tethered scarring, without which the defect may be exaggerated due to volumization surrounding a tethered defect. Additionally, the technique is prone to the same complications of the volumizing agent. There is some evidence that dermal fillers can be used to impart volume which can be useful for soft boxcar or rolling scars [8]. While this produces some improvement of the dermal volume to counter the atrophic nature of the scar itself, the results are dependent on the nature of the dermal filler. Injections of cross-linked hyaluronic acid stimulate collagen formation by dermal fibroblasts and ameliorate skin quality [9]. Several studies claim advantages of different fillers, and this is extensively discussed elsewhere [10]. However, the emerging consensus is that dermal fillers offer very little on their own in the management of atrophic acne scars and work best as combination therapy. Traditionally, fillers care combined with prior subcision [8]. The combination of dermal fillers with high-pressure blast-effect devices is discussed further in this section as part of our current regime.

\subsubsection{Dermal and Fat Autografting}

Two less common techniques used for correcting volume deficit in atrophic acne scarring are dermal grafting and fat autografting. They are included for completeness, as the practitioner may occasionally encounter patients having been on the receiving end of this technique. In dermal grafting, harvested dermis is processed and implanted into recipient areas. This traditional technique's limitations are that it is limited to atrophic scars at least $4 \mathrm{~mm}$ in diameter; necessitates pocket dissection for insetting the graft, which may simultaneously mean subcision; multiple incisions; and inclusion of epidermis may lead to inclusions and dermal cysts.

Lipotransfer involves harvesting, processing, and insetting adipose tissue, which then will be needed to survive by developing a blood supply from surrounding tissues. Evidence regarding its use in atrophic acne scarring is controversial. A combination of fat grafting and condensed nanofat has been successfully used to treat atrophic scars [11]. Other studies claim that this technique may improve atrophic acne scars and texture [12]. Azzam et al. claim that fat grafting proved to be more effective in the treatment of acne scars than ablative fractional $\mathrm{CO} 2$ laser treatment. However, it should be pointed out that this study's methodology suffered from limited validity. Follow-up was limited to 3 months after a single lesion of fractional $\mathrm{CO}_{2}$ laser therapy. Relatively low energies were used as well as a limited number of treatments. Currently, there is no evidence on the longterm success of this modality in the management of atrophic acne scarring [10].

\subsubsection{Isotretinoin Treatment}

Exposure to isotretinoic acid within 6 months was often cited a contraindication to treatment with a second modality [13], although more recently this view has been challenged. Historically, a few case series reported adverse events (development of keloids and hypertrophic scars, delayed healing) when patients recently completing isotretinoin treatment received dermabrasion and laser. "Spontaneous" keloids were also described in patients on isotretinoin. More recently, literature describes successful treatment of atrophic acne scarring, including fractional laser and dermabrasion; chemical peels in patients on isotretinoin challenge the traditional view of withholding treatment for 6-12 months. Rather, these adverse events result from individual variations in immunologic and inflammatory pathways. Early treatment of acne scars is critical for improved quality of life. The risk/benefit implications of treating the patient early need to be considered in the light of informed consent.

\subsubsection{State-of-the-Art and Combinatorial Approaches}

Most of the studies published today attempt to perform head-to-head comparison between different treatment modalities, in the attempt to identify the better option. This is understandable from a cost-benefit perspective due to the prohibitive outlay of some therapeutic modalities (• Fig. 41.1).

Here we concentrate on combinatorial approach (- Table 41.2) for the more taxing Goodman type 3-4 acne scars. There is a clear trend in the literature that favors combination treatments, and trends are now starting to emerge about useful synergies especially for the more severe acne types $[2,14]$.

\subsubsection{Fractional Radiofrequency (FRF)}

Fractional radiofrequency (FRF) transmits bipolar currents through contact electrodes or paired microneedles. This results in controlled, loco-temporal thermal dermal injury, inducing a wound-healing response. Clinically, this results in improved texture, tightening, and some improvement of skin clarity. There is consensus in the literature that three to six treatments provide optimal effects, ranging from $25 \%$ to $75 \%$ improvement and 
- Fig. 41.1 Morphological classification of post-acne scarring [13]

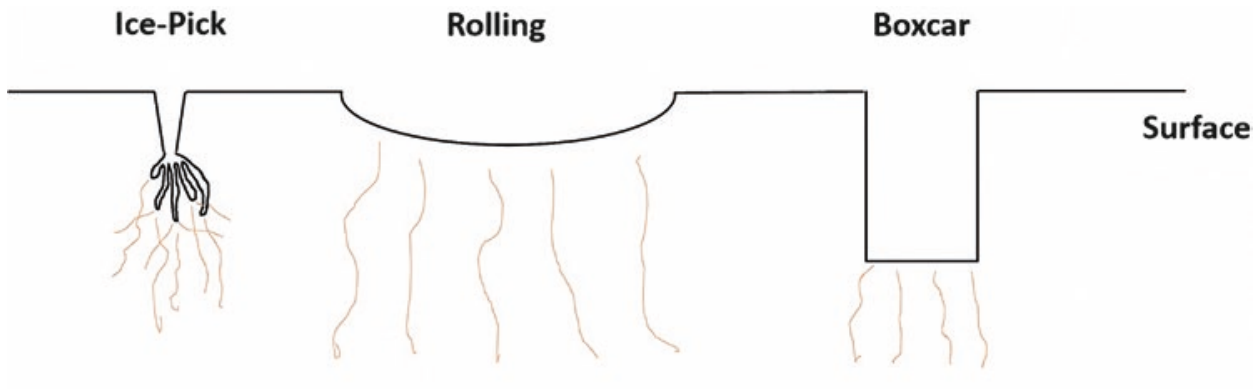

Rolling

- Table 41.2 Proposed combinatorial approach and treatment schedule for treatment of atrophic acne scarring

\begin{tabular}{|l|l|l|l|l|}
\hline Treatment & Effect & Repeats & Typical interval duration & Typical side effect duration \\
\hline $\begin{array}{l}\text { Bipolar radiofrequency } \\
\begin{array}{l}\text { Hyaluronic acid/high } \\
\text { pressure }\end{array}\end{array}$ & Regeneration & 5 & $45-60$ days & $5-7$ days \\
\hline \begin{tabular}{l} 
Fractional $\mathrm{CO}_{2}$ \\
\hline
\end{tabular} & Rermal revolumization & 3 & $45-60$ days & $1-2$ days \\
\hline
\end{tabular}

Schedule, temporal interval, and side effect duration are based on expert experience, using calibrated and maintained technology. Equipment settings vary between different manufacturers and versions

patient satisfaction. Radiofrequency with microneedles (RFM) delivers energy through microneedles (both insulated/non-insulated). The initial, mechanically induced microneedle wound-healing response [15] is followed by controlled thermal energy, up to $3.5 \mathrm{~mm}$ deep. This results in focal epidermal ablation, and controlled thermal damage to dermis, and, consequently, neocollagenesis, neoelastogenesis, and ground substance deposition [16]. Clinically, this results in textural amelioration, dermal density, and scar grading, whereas transepidermal water loss and sebum measurements did not change [17]. Some hybrid devices achieve this with a mixture of RF and galvanic energy. Transient posttreatment effects include pain, redness, mild swelling, and some crusting for up to 5 days. Track marks $(<6 \%)$ and postinflammatory hyperpigmentation $(<3 \%)$ have been reported. Lesions arising from ice-pick and hypopigmented acne scars do not respond optimally to this treatment modality from a revolumization perspective, but there may be benefit from resulting skin tightening. Due to the risk of cross-infecting unaffected areas, RFM is contraindicated in patients with any areas of active acne.

Pre- and post-therapeutic regimes are integral to a positive outcome. Makeup removal, and adequate drying of the skin, is essential to avoid short-circuiting and epidermal injury. In contrast to other authors [18], we have achieved acceptability with topical anesthesia only (lignocaine/tetracaine cream $70 \mathrm{mg} / \mathrm{g}$ ). The patient is advised a rigorous regime of UV protection $(\geq 50 \%)$ and emollients to accelerate healing and decrease the risk of PIH.

\subsubsection{High-Pressure Dermal Filler Deposition}

More recently, low-viscosity NAHA dermal fillers have been employed to replenish volume loss associated to volume loss. Early studies were performed using microdroplet applicators [19]. Even though these limited studies did report a beneficial effect, with recent improvements in high pressure, needle-less transdermal delivery systems have allowed the development of high-pressure transdermal hyaluronic acid delivery. The latter leads to a controlled "blast effect," releasing tethered scars while improving delivery of the NAHA to a controlled surface area and depth. The combined physicochemical blast deposition effect is purported to be synergistic and promotes sustained neocollagenesis [19]. Limited level 4 evidence does not allow pooling of data, but consistent beneficial effects have been reported on difficult-to-treat anatomical areas and skin types. Patel et al. used jet volumetric remodeling (JVR) technology to deliver crosslinked hyaluronic acid, using $40-45 \%$ pressure vs. levels 4-5 filling, and demonstrated a beneficial effect on icepick and boxcar scars. Although level 4 evidence is based on small case series, remarkable results are reported, on 
- Table 41.3 Evidence summary for JVR on the face and neck, since 2011, in the literature (English language)

\begin{tabular}{|l|l|l|l|l|l|l|l|}
\hline Ref. & Technique & $\begin{array}{l}\text { Reported } \\
\text { improvement - reduction } \\
\text { in Goodman score (\%) }\end{array}$ & $\begin{array}{l}\text { Mean age } \\
\text { (years) }\end{array}$ & $\begin{array}{l}\text { Follow-up } \\
\text { (months) }\end{array}$ & Area & $\begin{array}{l}\text { Skin types } \\
\text { (Fitzpatrick) }\end{array}$ \\
\hline$\left[\begin{array}{l}\boldsymbol{n}) \\
{[21]}\end{array}\right.$ & JVR/Histo/SP & 50 & 54.7 & 6 & Neck & Korean (II-V) \\
\hline$[22]$ & JVR/SP & 27.6 (face)/21.2 (neck) & 53.2 & $3-18$ & Face/neck & I-IV \\
\hline
\end{tabular}

$S P$ standard photography, JVR jet volumetric remodeling, Histo histological analysis. Search String "Pneumatic AND Hyaluronic"/ limits: English, human since 2010

a cohort of patients which are difficult to manage technically. Benefits include shortened procedure times and minimal downtime for a sustained improvement in the Goodman score. Murine model histological evidence supports the notion that the pneumatic injection of NAHA induces neocollagenesis and dermal thickening [20] (• Table 41.3).

\subsubsection{Laser}

Laser now enjoys a solid evidence base in acne treatment. Traditional ablative laser therapy involved wholesale, partial thickness ablation of diseased dermis. While this produced impressive results, it was associated with significant and prolonged side effects. In our practice this has been entirely overtaken by ablative fractional laser (AFL). Several ablative and non-ablative lasers have been described for the treatment of acne and which are well-described elsewhere [10].

In fractional laser, the laser beam is split into multiple hundred columns, which create noncontiguous zones of thermal injury. These microthermal zones result in noncontiguous columns of epidermal and dermal ablation, resulting in epidermal regeneration and neocollagenesis. There is consensus in the literature that repeat treatment is necessary, when offered in monotherapy, but this may not always be the case when offered as part of a regime intended to address the separate aspects of atrophic acne scarring pathology. Fractional carbon dioxide laser addresses both scar elevation and recontouring (• Fig. 41.2).

The skin stretch test of Goodman et al. [6] (- Table 41.1) is a good indicator with which to assess the amenability of scars for laser. Scars not correcting with a simple stretch test indicates that it will likely not correct with laser therapy but may require prior treatment with either punch excision or high-pressure injection of hyaluronic acid or, in select cases, subcision.

In a first pass, a narrow size scanning pattern is targeted at the scar base, with the aim of achieving lift (Deep Fx). The second pass targets the edges of sharpedged scar (such as boxcar scars), contouring it to a smoother scar edge (Deep Fx). In the third pass, active
FX is performed to feather out the troughs and crests of the scars. This is typically done at a fixed distance from the skin using a spacer. However, the authors prefer to use a "spray painting" technique, by holding the handpiece still further away from the skin, on increased density, resulting in a more efficient and effective resurfacing (- Table 41.4).

Using this technique, substantial improvement has been demonstrated histologically, and efficacy has been maintained for up to 3 years. The results appear to be more significant when compared to non-ablative modalities, albeit at the cost of increased downtime. It is important to advise patients appropriately regarding the importance of pre- and posttreatment regimes (- Table 41.5).

Non-ablative laser can also be useful in the correction of acne scarring. This modality trades off minimal downtime, against slower, lower degrees of improvement, compared to ablative laser. Particularly useful is Erbium glass $(1565 \mathrm{~nm})$ fractioned laser which may be used to refine dermal texture and contour. In shallow atrophic depressions requiring low energy for adequate penetration, high density may stimulate neocollagenesis, while the corollary settings on elevations may induce flattening.

Picosecond laser may also be used to the same effect with some distinct advantages. Hyperpigmentation may be effectively treated on collimated beam settings, with the picosecond duration resulting in light-reduced inflammatory response. In fractionated mode, picosecond laser results in light-induced optical breakdown (LIOB) which stimulates gentle neocollagenesis.

\subsection{Striae Albae}

Lineae albae present another difficult challenge, especially in darker-skinned individuals. Myriad treatments have been described, none entirely satisfactory. Several eponymous terms are used interchangeably, but we prefer the one proposed by Nardelli's "striae atrophicae," as it embodies the current histopathologic understanding [23]. 

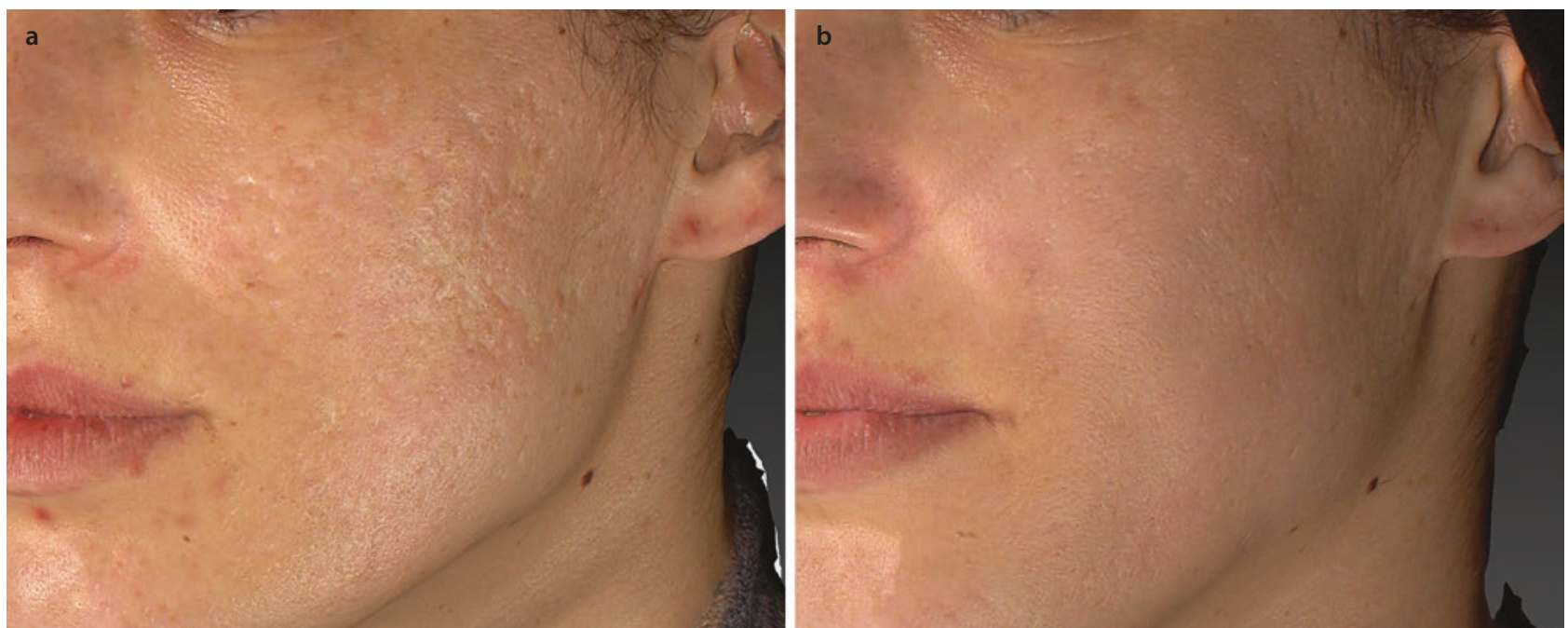

- Fig. 41.2 Figure 1a repesents the face before fractional $\mathrm{CO}_{2}$ procedure and $\mathbf{b}$ is the patient 6 months later

- Table 41.4 Suggested typical settings for post-acne AFL protocol

\begin{tabular}{|l|l|l|l|l|l|l|}
\hline Cycle & size & Pulses & Density $(\mathbf{\%})$ & Pattern cycle $(\mathbf{H z})$ & Energy $(\mathbf{m J})$ & Aim \\
\hline 1 DFX & 2 & 1 & $5-10$ & 300 & $15-20$ & Base of scar \\
\hline 2 AFX & 2 & 1 & 9 & 350 & $40-60$ & $\begin{array}{l}\text { Flange out Boxcar scars, } \\
\text { Handpiece at } 45^{\circ}\end{array}$ \\
\hline 3 DFX & & 1 & 15 & 300 & 17.5 & Tighten surround $^{\mathrm{a}}$ \\
\hline 4 AFX & & 1 & 3 & 125 & $100-$ & Re surface full face \\
\hline
\end{tabular}

$D F X$ Deep Fx ${ }^{\mathrm{TM}}, A F X$ Active $\mathrm{FX}^{\mathrm{TM}}$

${ }^{\text {a}}$ For severe scarring (optional)

- Table 41.5 Suggested pre- and posttreatment considerations

\begin{tabular}{|l|l|}
\hline Phase & Advice \\
\hline $\begin{array}{l}\text { Pretreatment } \\
\text { All patients }\end{array}$ & $\begin{array}{l}\text { Back to "normal shade" with } \\
\text { complete loss of holiday tan } \\
\text { SPF 50+ (every 2 h) }\end{array}$ \\
\hline Fitzpatrick 3-6 & $\begin{array}{l}\text { Initiate Kligman regime from 8 weeks } \\
\text { pretreatment, stop 2 weeks pre Rx }\end{array}$ \\
\hline tretinoin (0.02\%); hydroquinone (4\%); \\
vitamin c (3\%); hydrocortisone (1\%)
\end{tabular}

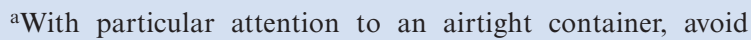
mucosal, periocular, and perioral areas, and avoid pooling in nasolabial sulcus
Compared to adjacent unaffected skin, striae albae present histologic evidence of attenuated dermal papillae, with the latter nearly entirely substituted with collagen fibers running parallel to the skin.

Trofolastin demonstrates level 2 evidence of positive results for their prophylactic use in SD [24]. Tehranchinia et al. [25] observed some degree of improvement in $80 \%$ of patients after two treatment sessions within a 4-week interval. However, $76.7 \%$ of patients remained dissatisfied. The authors concluded that this modality resulted in minimal improvement with mild side effects. It also is apparent that Trofolastin's mode of action is related to the deposition of hyaluronic activity [26]. Additionally, it is well established that fractional laser treatments induce long-term clinical and histological improvement of mature atrophic scars [26], including increased architectural reorganization toward normalization, such as collagen structure (from thick surface paralleled hyalinized bundles to uniform dense interwoven fibers with higher vascularization), and decreased inflammation. Unlike Taudorf et al., we do not perform stack pulsing. First as unless there is complete immobility, true stacking is 
impossible to achieve and, secondly, because stacking does increase risk of excessive thermal damage.

Clinical evidence supports the use of JVR with NAHA promoting sustained neocollagenesis and increased dermal depth, while the blast effect untethers the underlying scarring of lineae alba [27]. The combination of JVR to non-ablative fractional laser gives, in our opinion, a substantial improvement over both techniques used alone. NAFL then provides an effective tool to address dermal recontouring, by stimulating collagen synthesis in troughs and the opposite effect in surrounding areas. While effects of individual treatments appear to be long-lasting, we have also observed that one-off treatments are rarely as effective as repeated cycles spaced 6-8 weeks apart.

\subsection{Burn Atrophic Scars}

Great strides have been registered in acute burn management, resulting in increased burn survival, even with major and previously unsurvivable burns. As a result patients are presenting with increased requirements relating to morbidity and quality of life, arising both from the mechanism of injury and subsequent interventions required to safe life and limb. Atrophic burn scars form an important minority of burn scars. Often interspersed with hypertrophic counterparts, they result in wound instability and breakdown and contribute to poor cosmetic outcomes. The postoperative course of a burn scar is summarized symptomatically in - Table 41.6.

A plethora of lasers have been described in the treatment of atrophic scars ( Table 41.7), both non-ablative and ablative with an approximate cutoff of $200 \mathrm{~nm}$. Fractional ablation, first described by Mannstein [28], produces arrays of microscopic thermal damage zones (MTZs) throughout the epidermis and dermis, affecting only a part of the surface area, with consequent remodeling and neocollagenesis for up to 6 months after treatment with permanent results [29]. Less energy is required to achieve the desired depth $(\leq 2 \mathrm{~mm})$ of penetration in atrophic or flat scars, allowing higher fractionated densities to be used, depending on the device, $(\leq 10 \%)$.

Non-ablative fractional resurfacing (NAFR), in contrast, leaves the epidermis intact (ad dermis) whilst forming MTZs. A focused dermal injury instigates dermal remodeling and neocollagenesis [28]. The result is a bloodless cylindrical coagulation area within dermis. The clinical advantage is lower risk of infection and pigment alteration, as the epidermis is intact.

Post-procedure discomfort after AFR is surprisingly limited. Patients generally return to normal activity within 1 day, but downtime may be up to 7 days and requires several topical applications which may interfere with clothing and social activity. In contrast,
Table 41.6 Therapeutic burn phases

\begin{tabular}{|l|l|l|}
\hline Phase & Typical procedures & Aim \\
\hline Immediate & $\begin{array}{l}\text { Tracheostomy, } \\
\text { escharotomy }\end{array}$ & Life/limb saving \\
\hline Early & $\begin{array}{l}\text { Burn wound } \\
\text { excision and } \\
\text { grafting }\end{array}$ & $\begin{array}{l}\text { Excise dead tissue } \\
\text { Reduce evaporative } \\
\text { loss }\end{array}$ \\
\hline Intermediate & $\begin{array}{l}\text { Periorbital, } \\
\text { perioral, address } \\
\text { functional gain }\end{array}$ & $\begin{array}{l}\text { Protect special } \\
\text { senses } \\
\text { Improve ROM } \\
\text { deficit arising due } \\
\text { to increasing } \\
\text { mobility }\end{array}$ \\
\hline Late & $\begin{array}{l}\text { Incisional/ } \\
\text { excisional release }\end{array}$ & $\begin{array}{l}\text { Address functional } \\
\text { deficit } \\
\text { Improve range of } \\
\text { movement } \\
\text { Address pain, } \\
\text { pruritus }\end{array}$ \\
\hline
\end{tabular}

- Table 41.7 Wavelengths described from atrophic burn scars

\begin{tabular}{|c|c|c|c|}
\hline $\begin{array}{l}\text { Wavelength } \\
(\mathbf{n m})\end{array}$ & $\begin{array}{l}\text { Lasing } \\
\text { medium }\end{array}$ & Modality & Effect \\
\hline 10,600 & $\mathrm{CO}_{2}$ & Fractioned & $\begin{array}{l}\text { Lower }(\times 10) \\
\text { water affinity, } \\
\text { more } \\
\text { coagulation, } \\
\text { less bleeding, } \\
\text { favorable to } \\
\text { LADD }\end{array}$ \\
\hline 2790 & $\begin{array}{l}\text { Er, } \\
\text { Cr-YSGG }\end{array}$ & Fractioned & $\begin{array}{l}\text { More water } \\
\text { affinity, } \\
\text { narrower rim } \\
\text { of thermal } \\
\text { coagulation } \\
\text { around } \\
\text { MTZs }\end{array}$ \\
\hline 2940 & Er: YAG & Fractioned & \\
\hline $1540,1550,1565$ & Er: Glass & Fractionated & $\begin{array}{l}\text { For scars } \\
\text { with a } \\
\text { thickness } \\
\text { lower than } \\
2 \mathrm{~mm}\end{array}$ \\
\hline
\end{tabular}

$\mathrm{CO}_{2}$ carbon dioxide, $\mathrm{Er} Y A G$ erbium-doped yttrium aluminum garnet, $E r, C r-Y S G G$ erbium, chromium-doped yttrium scandium-gallium-garnet, $L A D D$ laser-assisted drug delivery

NAFR requires far less downtime, dyschromia, PIH, with lower analgesia requirements, at the expense of more treatment sessions being required. In consideration of these reasons, for flat or atrophic scars, there is 
emerging consensus in the literature that NAFR is the treatment of choice [30]. We also suspect that such wide variety of data exists in part from the prohibitive cost of each technology. Having access to the entire range of technologies in our center, we favor the use of NAFR Er:YAG to raise the base of atrophic scars on higherdensity settings.

While the optimal timing of fractional laser therapy is not yet determined, current trends in the literature over the past 5 years favor earlier intervention. Scars of any age can be considered for fractional resurfacing. In practice, the contrast between postoperative regimes required by laser and complex burn surgery poses practical limits on how early a laser intervention may be successfully offered. Notwithstanding, younger scars are more susceptible to remodeling, and some studies now suggest that the ideal timeframe may be as early as 4-12 weeks post-injury, repeated every $1-2$ months until response plateaus or the therapeutic aims are attained and may help in scar remodeling, reduce contracture rates, and expedite rehabilitation [31].

Vascular Laser Lasers targeting abnormal scar proliferation have the potential to improve scar characteristics. A number of wavelengths are often used for this purpose, including millisecond range potassium titanyl phosphate (KTP) $532 \mathrm{~nm}$, pulse dye laser (PDL) $595 \mathrm{~nm}$, and neodymium:yttrium aluminum garnet (Nd:YAG) $1064 \mathrm{~nm}$. Although the primary target of PDL is hemoglobin, its mechanism of action is not fully understood. After multiple treatments, PDL results in some softening, flattening, and smoothening [32]. However, melanin acts as a potential competitor; therefore, conservative settings need to be used in darker individuals.

Fractioned picosecond modality laser has the potential to produce light-induced optical breakdown, limited to the dermis, which may stimulate dermal inflammation, remodeling, and neocollagenesis. There is still some controversy regarding the timing of appearance and significance of microscopic epidermal necrotic debris (MEND). In one such study, this phenomenon was noted as early as $3 \mathrm{~h}$ (post-pico-532 nm) and within $24 \mathrm{~h}$ (both 532 and $1064 \mathrm{~nm}$ wavelengths) [6].

Burn reconstruction really starts in the immediate postburn period with adequate first aid therapy that limits the zone of stasis and hyperemia and careful, multimodality management including judicious debridement and maximal attention to dermal sparing. Fractional laser resurfacing for atrophic wounds is an integral part of this armamentarium. Additionally, our recent experience suggests that JVR (NAHA) is a useful adjunct in achieving revolumization of selected atrophic burn wound reconstructions. In particular, resurfacing with split thickness skin grafts often leads to a honeycombed appearance, reduced elasticity, and a feeling of tightness, due to the minimal dermal component of a split-thickness skin graft. Our early experience with this technology has produced excellent results when used in tandem with fractional laser, where we have observed synergistic dermal "re-plumping" and substantial improvement of skin texture.

\subsection{Conclusion}

Atrophic scars present a significant challenge to the reconstructive specialist, with acne, linea albae, and burns being topics worthy of special consideration. Optimal treatment is not based on superiority of one particular treatment over another but rather by the specialist's ability to precisely identify the component parts of the presenting complaint and bringing his entire armamentarium to bear. We believe, based on experience and balance of current evidence, that combined, repeat treatment produces the best results and that these must be carefully balanced against the relative costs: physical, social, and economic, in consideration of each patient's individual needs.

\section{Take Home Messages}

- Atrophic scarring is the final common pathway resulting from reduced matrix regeneration and focally reduced collagen production.

- Addressing patient concerns, expectations, and attitude to risk/benefit is key.

- Techniques may be considered according to their principal mode of action: resurfacing and tightening, dermal lifting techniques, and dermal volumization techniques.

- Acne scars affect physical, psychological, and social well-being. Involvement of multiprofessional advice is important.

- In appropriately selected patients, combined RFM-JVR-AFL treatment, tailored to individual needs, is more likely to produce appropriate results.

- Repeat treatment is likely to be needed.

- Color laser may lead to substantial improvement in dyschromias.

\section{References}

1. Poetschke J, Gauglitz GG. Current options for the treatment of pathological scarring. J Dtsch Dermatol Ges. 2016;14(5):46777. https://doi.org/10.1111/ddg.13027. [published Online First: 2016/04/28].

2. Zaleski-Larsen LA, Fabi SG, McGraw T, et al. Acne scar treatment: a multimodality approach tailored to scar type. Dermatol Surg. 2016;42:S139-S49. 
3. Koo J. The psychosocial impact of acne: patients' perceptions. $\mathbf{J}$ Am Acad Dermatol. 1995;32(5):S26-30.

4. Halvorsen JA, Stern RS, Dalgard F, et al. Suicidal ideation, mental health problems, and social impairment are increased in adolescents with acne: a population-based study. J Investig Dermatol. 2011;131(2):363-70.

5. Layton A, Henderson C, Cunliffe W. A clinical evaluation of acne scarring and its incidence. Clin Exp Dermatol. 1994; 19(4):303-8.

6. Balu M, Lentsch G, Korta DZ, et al. In vivo multiphotonmicroscopy of picosecond-laser-induced optical breakdown in human skin. Lasers Surg Med. 2017;49(6):555-62.

7. Linkner RV, On SJ, Haddican M, et al. Evaluating the efficacy of photodynamic therapy with $20 \%$ aminolevulinic acid and microdermabrasion as a combination treatment regimen for acne scarring: a split-face, randomized, double-blind pilot study. J Clin Aesthet Dermatol. 2014;7(5):32.

8. Lee JW, Kim BJ, Kim MN, et al. Treatment of acne scars using subdermal minimal surgery technology. Dermatol Surg. 2010;36(8):1281-7.

9. Wang F, Garza LA, Kang S, et al. In vivo stimulation of de novo collagen production caused by cross-linked hyaluronic acid dermal filler injections in photodamaged human skin. Arch Dermatol. 2007;143(2):155-63.

10. Bhargava S, Cunha PR, Lee J, et al. Acne scarring management: systematic review and evaluation of the evidence. Am J Clin Dermatol. 2018;19(4):459-77.

11. Gu Z, Li Y, Li H. Use of condensed nanofat combined with fat grafts to treat atrophic scars. JAMA Facial Plast Surg. 2018;20(2):128-35.

12. Azzam O, Atta A, Sobhi R, et al. Fractional $\mathrm{CO}(2)$ laser treatment vs autologous fat transfer in the treatment of acne scars: a comparative study. J Drugs Dermatol. 2013;12(1):e7-e13.

13. Jacob CI, Dover JS, Kaminer MS. Acne scarring: a classification system and review of treatment options. J Am Acad Dermatol. 2001;45(1):109-17.

14. Goodman GJ. Treating scars: addressing surface, volume, and movement to expedite optimal results. Part 2: more-severe grades of scarring. Dermatol Surg. 2012;38(8):1310-21.

15. Doddaballapur S. Microneedling with dermaroller. J Cutan Aesthet Surg. 2009;2(2):110-1. https://doi.org/10.4103/09742077.58529.

16. Tanaka Y. Long-term three-dimensional volumetric assessment of skin tightening using a sharply tapered non-insulated microneedle radiofrequency applicator with novel fractionated pulse mode in asians. Lasers Surg Med. 2015;47(8):626-33. https://doi.org/10.1002/lsm.22401.

17. Cho SI, Chung BY, Choi MG, et al. Evaluation of the clinical efficacy of fractional radiofrequency microneedle treatment in acne scars and large facial pores. Dermatol Surg. 2012;38(7 pt1):1017-24. https://doi.org/10.1111/j.1524-4725.2012.02402.x.
18. Ibrahim O, Munavalli GS, Dover JS. Radiofrequency with microneedling. Adv Cosmet Surg. 2018;1(1):109-15. https://doi. org/10.1016/j.yacs.2018.03.001.

19. Halachmi S, Ben DA, Lapidoth M. Treatment of acne scars with hyaluronic acid: an improved approach. J Drugs Dermatol. 2013;12(7):e121-3.

20. Kwon T-R, Seok J, Jang J-H, et al. Needle-free jet injection of hyaluronic acid improves skin remodeling in a mouse model. Eur J Pharm Biopharm. 2016;105:69-74. https://doi.org/10.1016/j. ejpb.2016.05.014.

21. Han TY, Lee JW, Lee JHK, et al. Subdermal minimal surgery with hyaluronic acid as an effective treatment for neck wrinkles. Dermatol Surg. 2011;37(9):1291-6.

22. Levenberg A, Halachmi S, Arad-Cohen A, et al. Clinical results of skin remodeling using a novel pneumatic technology. Int $\mathrm{J}$ Dermatol. 2010;49(12):1432-9.

23. Nardelli L. Importanza semiologica delle "striae cutis atrophicae". Boll Sez Region Soc Ital Dermatol. 1936;1:46.

24. Ud-Din S, McGeorge D, Bayat A. Topical management of striae distensae (stretch marks): prevention and therapy of striae rubrae and albae. J Eur Acad Dermatol Venereol. 2016;30(2):21122. https://doi.org/10.1111/jdv.13223. [published Online First: $10 / 20]$.

25. Tehranchinia Z, Mahboubianfar A, Rahimi H, et al. Fractionated $\mathrm{CO}(2)$ laser in the treatment of striae alba in darker skinned patients - a prospective study. J Lasers Med Sci. 2018;9(1):15-8. https://doi.org/10.15171/jlms.2018.04. [published Online First: $12 / 26]$.

26. Ash K, Lord J, Zukowskl M, et al. Comparison of topical therapy for striae alba (20\% glycolic acid $/ 0.05 \%$ tretinoin versus $20 \%$ glycolic acid/10\% L-ascorbic acid). Dermatol Surg. 1998; 24(8):849-56.

27. Cassuto D. Case report: effective treatment of striae distensae using pneumatic injection of hyaluronic acid. Available online on elogioasia.com.

28. Manstein D, Herron GS, Sink RK, et al. Fractional photothermolysis: a new concept for cutaneous remodeling using microscopic patterns of thermal injury. Lasers Surg Med. 2004;34(5):426-38.

29. Stewart N, Lim AC, Lowe PM, et al. Lasers and laser-like devices: part one. Australas J Dermatol. 2013;54(3):173-83.

30. Carniol PJ, Hamilton MM, Carniol ET. Current status of fractional laser resurfacing. JAMA Facial Plast Surg. 2015;17(5): 360-6.

31. Waibel JS, Rudnick A. Current trends and future considerations in scar treatment. Seminars in cutaneous medicine and surgery. Semin Cutan Med Surg. 2015;34(1):13-6.

32. Alster TS, Williams CM. Treatment of keloid sternotomy scars with $585 \mathrm{~nm}$ flashlamp-pumped pulsed-dye laser. Lancet. 1995;345(8959):1198-200.

Open Access This chapter is licensed under the terms of the Creative Commons Attribution 4.0 International License (http://creativecommons. org/licenses/by/4.0/), which permits use, sharing, adaptation, distribution and reproduction in any medium or format, as long as you give appropriate credit to the original author(s) and the source, provide a link to the Creative Commons license and indicate if changes were made.

The images or other third party material in this chapter are included in the chapter's Creative Commons license, unless indicated otherwise in a credit line to the material. If material is not included in the chapter's Creative Commons license and your intended use is not permitted by statutory regulation or exceeds the permitted use, you will need to obtain permission directly from the copyright holder. 